IZA DP No. 4251

Subsidizing Vocational Training for Disadvantaged Youth in Developing Countries:

Evidence from a Randomized Trial

Orazio P. Attanasio

Adriana D. Kugler

Costas Meghir

June 2009 


\title{
Subsidizing Vocational Training for Disadvantaged Youth in Developing Countries: Evidence from a Randomized Trial
}

\author{
Orazio P. Attanasio \\ University College London, \\ IFS, NBER and CEPR \\ Adriana D. Kugler \\ University of Houston, NBER, CEPR, CReAM, IZA \\ and Stanford Center for the Study of Poverty and Inequality \\ Costas Meghir \\ University College London, \\ IFS, CEPR and IZA

\section{Discussion Paper No. 4251 \\ June 2009} \\ IZA \\ P.O. Box 7240 \\ 53072 Bonn \\ Germany \\ Phone: +49-228-3894-0 \\ Fax: +49-228-3894-180 \\ E-mail: iza@iza.org
}

\begin{abstract}
Any opinions expressed here are those of the author(s) and not those of IZA. Research published in this series may include views on policy, but the institute itself takes no institutional policy positions.

The Institute for the Study of Labor (IZA) in Bonn is a local and virtual international research center and a place of communication between science, politics and business. IZA is an independent nonprofit organization supported by Deutsche Post Foundation. The center is associated with the University of Bonn and offers a stimulating research environment through its international network, workshops and conferences, data service, project support, research visits and doctoral program. IZA engages in (i) original and internationally competitive research in all fields of labor economics, (ii) development of policy concepts, and (iii) dissemination of research results and concepts to the interested public.
\end{abstract}

IZA Discussion Papers often represent preliminary work and are circulated to encourage discussion. Citation of such a paper should account for its provisional character. A revised version may be available directly from the author. 


\section{ABSTRACT}

\section{Subsidizing Vocational Training for Disadvantaged Youth in Developing Countries: Evidence from a Randomized Trial ${ }^{*}$}

This paper evaluates the impact of a randomized training program for disadvantaged youth introduced in Colombia in 2005. This randomized trial offers a unique opportunity to examine the impact of training in developing countries. We use originally collected data on individuals randomly offered and not offered training. The program raises earnings and employment, especially for women. Women offered training earn 18\% more and have a 0.05 higher probability of employment than those not offered training, mainly in formal sector jobs. Costbenefit analysis of these results suggests that the program generates much larger net gains than those found in developed countries.

JEL Classification: $\quad$ C21, I38, J24

Keywords: vocational training, randomized trials

Corresponding author:

Adriana D. Kugler

University of Houston

Department of Economics

204 McElhinney Hall

Houston, TX 77204-5019

USA

E-mail: adkugler@uh.edu

\footnotetext{
"We are extremely grateful to the teams at SEI and Econometria for their help with the coordination of the project and with the collection of the data. We are also very grateful to Luis Carlos Corral at the Department of Planning for hearing our plea and supporting us in carrying out the randomization. We thank Alberto Abadie, Josh Angrist, Abhijit Banerjee, Jere Behrman, Esther Duflo, Mark Duggan, Nada Eissa, Bill Evans, David Francis, Ted Gayer, John Haltiwanger, Jim Heckman, Judy Hellerstein, Harry Holzer, Laura Juárez, Michael Kremer, César Martinelli, Ted Miguel, Jesse Rothstein and Jeff Smith for very helpful comments, as well as to seminar participants at the Harvard/MIT Development Seminar, Georgetown University, the University of Maryland, Case Western, ITAM, UCLA, UC Irvine, University of Notre Dame, the World Bank, the 2008 SOLE meetings, the IZA/World Bank Employment and Development Conference, the IZA/World Bank Conference on Evaluation of Labor Market Programs in Developing Countries and at the TIMES seminar at the University of Houston. Adriana Kugler gratefully acknowledges financial support from a University of Houston GEAR grant. Orazio Attanasio and Costas Meghir's research have been financed by an ESRC professorial fellowship and the ESRC centre at the IFS.
} 


\section{Introduction}

Youth unemployment is exceptionally high in Latin America, to the point that it triples the unemployment rate of adults in the region. Youth unemployment is even more of a problem among those at the lower end of the income distribution. In the late 1990s, the youth unemployment rate in the first income quartile was 13 times higher than the youth unemployment rate in the fourth quartile in Honduras, 9 times higher in Argentina, 8 times higher in Bolivia, 5 times higher in Chile and 2 times higher in Colombia and Panama. ${ }^{1}$ This is a sad start to the beginning of anyone's labor market experience and likely affects adult employment prospects. At the same time, these high youth unemployment rates, especially among the poor, raise concerns about young people engaging in criminal activities given the lack of better prospects. In fact, violent activity among young people has contributed to the steep rise in urban violence during the 1990s in Latin America, with Colombia, Brazil, Mexico and Venezuela heading the list. In addition to the usual concerns about youth unemployment in terms of poor future labor market prospects and increased crime, there is the concern that living standards may be affected substantially by youth unemployment in Latin America, where young people, and even children, are substantial contributors to household income.

Lack of skills is thought to be one of the key determinants of major social problems such as unemployment, poverty and crime as well as a key limitation to growth in developing countries. Education programs, mostly targeted at reducing the cost of attending school, have, thus, been at the heart of developing country policies. While early interventions that reduce the cost of education and improve the quality of education at the

\footnotetext{
${ }^{1}$ See Hopenhayn (2002).
} 
primary and secondary levels may be key for long-term poverty alleviation (see, e.g., Carneiro and Heckman (2003)), these interventions may arrive too late for those who are already close to the end of their schooling or in their early post-schooling years. ${ }^{2}$

Although there are good reasons to advocate the use of training programs for youth in developed countries, there is little reliable evidence on the impact of training on improving the labor market standing of the poor in the developed country context and even less evidence in the developing country context. Indeed, mixed results of careful evaluations of government training programs in the US, the UK and other industrialized countries justifies some a priori skepticism as to whether such interventions can deliver positive and cost-effective results, helping poverty alleviation in developing countries. ${ }^{3}$

The picture, however, could be different in developing countries, as one may expect the returns to training to be higher where the levels of skills of the population are very low to begin with. A number of training programs for disadvantaged workers have been introduced in recent years in many Latin American countries, including Argentina, Brazil, Chile, Colombia, the Dominican Republic, Panama, Peru and Uruguay, and indeed suggest positive returns. ${ }^{4}$ However, these programs have largely been evaluated using non-experimental techniques casting some doubt on the validity of the estimates,

\footnotetext{
${ }^{2}$ Innovative interventions in developing countries include: subsidies to attend private schools (see, e.g., Angrist et al. (2002, 2006), Bettinger et al. (2007), and Barrera-Osorio et al. (2008)), conditional cash or inkind transfers to families who send their kids to school (see, e.g., Attanasio et al. (2005), Behrman et al. (2005), Glewwee and Olinto (2004) and Kremer and Vermeersh (2005)), and teacher incentives and extra teaching time aimed at increasing quality (see, e.g., Banerjee et al. (2007), and Muralidharan and Sundararaman (2006)).

${ }^{3}$ See LaLonde (1995) and Heckman, LaLonde and Smith (1999) for surveys of the literature; see Carneiro and Heckman (2003) and Heckman and Krueger (2003) for a general discussion of human capital policies; and see Holzer (2007) for a discussion of employment policies for the poor. Also, see LaLonde (1986), Card and Sullivan (1988) and Burghardt and Schochet (2001) for some selected studies of randomized training programs in the U.S.

${ }^{4}$ See Betcherman, Olivas and Dar (2004), Elias et al. (2004), and Card et al. (2007).
} 
which could be biased if there is selection into the program on the basis of unobservables. $^{5}$

An intervention in Colombia, combined with a randomized experiment, gives us an almost unique opportunity to offer reliable evidence on the value of training in developing countries. The program "Jóvenes en Acción” (which translates as Youth in Action) was introduced between 2001 and 2005 and provided 3 months of in-classroom training and 3 months of on-the-job training to young people between the ages of 18 and 25 in the two lowest socio-economic strata of the population. Training institutions in the seven largest cities of the country chose the courses to be taught as part of the program and received applications. Each institution was then asked to select more individuals than they had capacity for each of the classes it offered. Subsequently, the program randomly offered training to as many people as there were slots in each class, among the individuals initially chosen by the training institutions. The remaining youths were then used as a control group not selected into training. The advantage of this design is that it attempts to capture the process of trainee selection as it would take place in practice, rather than force the training institutions to train individuals they would otherwise not choose to train. This means that the results focus on the population of individuals good enough to be accepted into such a program.

The results we obtain show large program effects. Comparisons between those offered and not offered training show that those offered training do better in the labor

\footnotetext{
${ }^{5}$ Most studies evaluating the impact of vocational training in Latin America try to eliminate selection biases by using standard matching methods. The study by Galdo and Chong (2006) for Peru compares the effects of higher and lower quality training on labor market outcomes using difference-in-differences parametric and ridge matching approaches. A related study by Malamud and Pop-Eleches (2009) instead compares the effects of vocational and general education in a transition economy by using a regression discontinuity design.
} 
market. The comparisons between individuals offered and not offered training are known as intention-to-treat (ITT) effects. In the case of “Jóvenes en Acción,” the intention-totreat effects are likely to be very close to the average effects of training because there is close to full compliance. In particular, the probability of receiving training is about 0.97 higher for those who were initially offered training relative to those who were not. Few individuals who are not initially offered a slot in a course are eventually trained, and even fewer of those individuals who were offered a slot turn down the opportunity to train.

Intention-to-treat effects show that those offered training are more likely to be employed. In particular, being offered training increases paid employment by about $6.8 \%$. The monthly wage and salary earnings of those offered training are about 25,500 Colombian pesos (US\$11) or 12\% higher than those for individuals not offered training. Moreover, the likelihood of being employed in jobs that offer non-wage benefits and of having a written contract is 0.05 higher for those offered training. In fact, the gains from training seem largely linked to employment in the formal sector, as only those that get jobs in the formal sector experience wage and salary gains after training. When we examine separate effects for women and men, the results show that these effects are mainly driven by women. Women offered training are more likely to have paid employment and to be employed in the formal sector and earn higher overall and formal wages. While the results for men are qualitatively similar, these are imprecisely estimated.

These results stand in strong contrast to most of the results obtained in developed countries and, in particular, in the U.S. (see, e.g., Heckman and Krueger (2003), Burghardt and Schochet (2001), and Heckman, LaLonde and Smith (1999)). In these 
countries the effects are often small, if at all positive, and it is often unclear whether they are worth implementing from a cost-benefit perspective. On the other hand, these results are consistent with non-experimental evaluations of training programs for disadvantaged youth introduced in recent years in a number of Latin American countries, including Argentina, Brazil, Chile, Colombia, Dominican Republic, Panama, Peru and Uruguay. Like our paper, for the most part, the results from these non-experimental analyses show positive effects on earnings, especially for women. An exception to these nonexperimental evaluations in developing countries is the work by Card et al. (2007) based on a randomized trial in the Dominican Republic which finds positive, though insignificant, effects on earnings and on the probability of getting a job with health insurance of similar magnitudes we find here. The authors attribute the insignificant effects to their small sample sizes. ${ }^{6}$

The rest of the paper proceeds as follows. Section 2 provides some background on the basic design and implementation of the program Jóvenes en Acción. Section 3 describes the experimental design, as well as the collection of the data. Section 4 provides descriptive statistics and comparisons between the treatment and control groups at baseline. Section 5 presents first-stage results on the impact of a training offer on actual training, and then presents estimates of the intention-to-treat effects of the program on labor market outcomes, controlling for course fixed effects and pre-treatment characteristics. Section 6 shows cost-benefit analyses and Section 7 concludes.

\footnotetext{
${ }^{6}$ Hjort et al. (2009) discuss the work they are currently conducting on a randomized training trial in Kenya.
} 


\section{Background and Description of the Program}

In 1998 Colombia was hit by the strongest recession in almost 60 years. While the economy had an average GDP growth of 3\% for the entire decade of the 1990s, in 1999 Colombia's GDP growth fell to $-6.0 \%$. The economy only recovered to 3\% GDP growth again in 2003.

Given the absence of safety nets in the Colombian economy and the devastating effect that the recession was having on the poorest segments of the population, in 2001 the Colombian government introduced three new social programs to help those hardest hit by the recession, ${ }^{7}$ which were financed with loans from the World Bank and the InterAmerican Development Bank. The three programs were "Familias en Acción,” "Empleo en Acción,” and “Jóvenes en Acción.” The first was a conditional cash transfer program, similar to the Progresa program in Mexico, which provides stipends for rural families conditional on sending their children to school and providing health checks to the children. The second was a workfare-type program, similar to "Trabajar" in Argentina, which provided temporary government employment to low-income adults. The third, “Jóvenes en Acción,” which is the program evaluated in this study, provided subsidized training to poor young people living in urban areas.

The program “Jóvenes en Acción” reached 80,000 young people (or approximately $50 \%$ of the target population) and was given to various cohorts over a period of four years. The first cohort received training in 2002 and the last one in 2005. This analysis evaluates this last cohort.

\footnotetext{
${ }^{7}$ It is worth noting that unemployment insurance did not exist in Colombia until 2003 when it was introduced by legislation.
} 
The program was targeted to young people between the ages of 18 and 25, who were unemployed and who were placed in the two lowest deciles of the income distribution. The program spent US\$60 million or US\$750 per person and was offered in the seven largest cities of the country: Barranquilla, Bogotá, Bucaramanga, Cali, Cartagena, Manizales and Medellin.

Training consisted of 3 months of classroom training and 3 months of on-the-job training. Classroom training was provided by private training institutions, which had to participate in a bidding process to be able to participate in the program. The training institutions were selected based on the following criteria: legal registration, economic solvency, quality of teaching, and ability to place trainees after the classroom phase into internships with registered employers. In 2005, there were a total of 114 training institutions offering 441 different types of courses to 989 classes with a total of 26,615 slots for trainees, which means that the average class had 27 students. Training courses provided vocational skills in a diverse number of occupations. ${ }^{8}$ It is important to stress that the private training institutions played a fundamental role in determining what courses were offered, how they were marketed and how they were designed. The average number of hours of training was about 7 and a half hours per day. ${ }^{9}$ Of the participating training institutions $43.2 \%$ were for profit and 56.8\% were non-profit. Training institutions were paid according to market prices and were paid conditional on completion of training by the participants of the program.

\footnotetext{
${ }^{8}$ Courses included training for: taxi and bus drivers; office assistants; call center operators; nurses' and physicians' assistants; pharmacy assistants; hairdressing and cosmetology assistants; inventory assistants; archival assistants; pre-school teacher assistants; cashiers; payroll assistants; assistants for computer installation and maintenance; textile operators; wood-cutting machine operators; carpentry assistants, plumber assistants, and electricians’ assistants.

${ }^{9}$ The average weekly hours of classroom training was 61.2 and the standard deviation was 16.4.
} 
On-the-job training was provided by legally registered companies, which provided unpaid internships to the participants. There were a total of 1,009 companies that participated in the program. These companies operated in manufacturing (textiles, food and beverages, pharmaceuticals, and electricity), retail and trade, and services (including security, transportation, restaurants, health, childcare, and recreation). The internships offered an average of close to 2 hours of training per day. ${ }^{10}$

The program provided a cash transfer of about US\$2.20 per day to male and female trainees without young children throughout the 6 months in the program to cover for transportation and lunch, which was provided conditional on participation in the program. The amount was increased to about US $\$ 3.00$ per day for women with children under 7 years of age to help cover for childcare expenses.

\section{Experimental Design and Data Collection}

\subsection{Experimental Design}

As a rule the earnings of trainees and non-trainees are unlikely to be directly comparable for reasons that have been extensively discussed (see Heckman, LaLonde and Smith (1999)). Random assignment allows us to overcome selection bias in the evaluation of Youth in Action.

The randomization worked as follows: each training institution provided a list of up to $50 \%$ more applicants than they had capacity for each of the classes they offered; then, these individuals were randomly offered or not offered a position in a class at each training institution using the special information system set up to register applicants into the program. The program was designed to randomly assign individuals to each class at

\footnotetext{
${ }^{10}$ The average weekly hours of on-the-job training was 14.7 and the standard deviation was 20.3.
} 
each training institution by a centralized information system by January $18^{\text {th }}$, 2005. Since the total number of slots per class was fixed but the number of people pre-selected in the training list varied by class in each training institution, the probability of being offered a spot in a course also differed by training institution. ${ }^{11}$

If the individuals who were initially assigned to the program did not accept the training opportunity, then the training institutions were allowed to fill these slots with the next individual in the class lists randomly generated by the information system. In addition, individuals who were not initially offered a slot could request to be released from the waiting list in a particular class and to apply to other classes within the same training institutions or in other institutions. In practice, there were only 56 individuals in our sample who did this. This means that although, for the most part, the trainees were randomly assigned, these 56 individuals (i.e., $1.29 \%$ of our sample) who initially did not get assigned to treatment but got trained and the 8 (i.e., $0.18 \%$ of our sample) who turned down training may be self-selected and introduce a bias. Fortunately, we have information on the initial random assignment, so that our analysis is based on the initial offer of training and not on actual training. ${ }^{12}$ However, the number of non-compliers was so small that, in practice, it does not matter for the results we obtain.

An advantage of this study is that the availability of training was randomly assigned among those who chose to apply for training and who were selected as suitable by the training institutions. Moreover, by asking training institutions to select more candidates than they had places, the experiment comes closer to identifying the effect

\footnotetext{
${ }^{11}$ The median probability of being offered training was 0.815 and the average probability of being offered training was 0.85 with a standard deviation of 0.12 .

${ }^{12}$ This is an important difference with the Card et al. (2007) analysis, which is based on actual training as opposed to initial assignment to training and which is subject to much more non-compliance.
} 
following an overall expansion of the program to a population, which currently does not have full access.

Given the design of the experiment and the limited non-compliance, the effect of the program is almost the same as the weighted average of comparisons of outcomes between the groups that were and were not trained in each class. However, while individuals were randomly assigned to each class at each training institution, our data only have information on each type of course offered by each training institution. Thus, if a training institution offered 2 classes for hairdressers or 3 classes for wood-cutting machine operators, we cannot compare treatment and control individuals within class but rather within each type of course at a training institution.

In addition, some of the multiple classes were created after January $18^{\text {th }}$ when the initial random assignment was done. Some individuals were assigned on February 1, February 10, April 29 and even as late as May $6^{\text {th }}$. Given that training institutions got paid by the program on the basis of how many people finished training, some institutions appear to have found ways not to comply with the randomization by initiating courses after the indicated date. In our analysis, we eliminate problematic institutions in which the treated and control individuals were assigned after the initial date when randomization took place. This does not cause any bias because the randomization is always within institutions.

\subsection{Data Collection}

Given the design of the randomization described above, the data set used for this evaluation, includes a treatment and a control group, in each of the seven cities covered by the program. There were two stages to the data collection: the first stage conducted a 
baseline survey which collected information on the individuals in the sample before their participation into the program, and a second stage which conducted a follow-up survey and collected information on individuals after the end of the two components of training (i.e., classroom and on-the-job training).

We chose the number of interviews to be able to detect effects similar to those found in other programs based on a $10 \%$ level of significance. This yielded a sample of 3,300 with 1,650 in each group. Taking an ex-ante pessimistic view on attrition, ${ }^{13}$ we increased the sample to 2,040 and 2,310 for the treatment and control groups, respectively.

The baseline sample includes 2,066 individuals in the treatment group and 2,287 controls. The sample was stratified by city and sex, with equal numbers of women and men in each city. The baseline data (before the provision of training) was collected in January 2005 either before the beginning of the training program or during the first week of classes to minimize any influence of participation in the program on the interviewees' responses. However, since, as pointed out above, some individuals were assigned to the treatment and control groups after the initial random assignment, the baseline interviews for individuals assigned after January were conducted after the courses were already under way. We eliminate these non-randomly assigned individuals out of the sample, which account for about $17 \%$ of the sample. In addition, given that those training institutions that trained individuals under the program after the initial random assignment were probably trying to get around the experimental design, we also eliminated any institutions which had more than $10 \%$ of individuals signed up after January $18^{\text {th }}$. This

\footnotetext{
${ }^{13}$ The expected attrition used was $24 \%$ for the program participants and $40 \%$ for the non-program participants.
} 
accounts for another $15 \%$ of the sample, so that our final baseline sample consists of 2,859 individuals. ${ }^{14}$

The follow-up interviews were carried out between August and October of 2006 or between 19 and 21 months after the beginning of the program (since the program started at the end of January 2005) with the idea of allowing at least one year since the completion of the program to evaluate its effectiveness in terms of labor market outcomes.

Since there were concerns with attrition, especially for a highly mobile group of young people in the lowest socio-economic strata of the population, telephone updates were conducted on November 2005 or 4 months after the completion of the program. These telephone follow-ups verified the basic personal information of the baseline interviewees and got up-to-date contact information, including addresses and telephone numbers, for those who had moved or were about to move. Telephone numbers were available for 4,298 of the 4,353 individuals initially interviewed at baseline, so that there were missing phone numbers only for 55 individuals or $2 \%$ of those initially interviewed. Of the ones with a phone number, 3,736 or $85.8 \%$ were reached. Of these 163 or $4.36 \%$ had moved and it was not possible to get new contact information. Out of the 617 who were not reached, $71 \%$ had their phone lines cut off or not working. However, personal visits were then conducted to update the information of these 617 individuals.

\footnotetext{
${ }^{14}$ We also try leaving out any institutions with any individuals assigned after January and leaving out institutions which had more than $5 \%$ of individuals assigned after January. The results are similar, but somewhat less precise. Results based on all the original observations in the sample (i.e., including those who were not randomly assigned) yield similar though somewhat larger intention-to-treat effects on employment and earnings and also positive effects on hours and days worked, but show differences in pretreatment characteristics between the treatment and control groups.
} 
The complete follow-up in-person interviews were carried out between 9 and 11 months after the telephone update. The follow-up was conducted using the initial list of individuals in the baseline with the contact information updated by telephone in November. In total, there were 3,549 individuals interviewed in the follow-up approximately one year after the training program finished or $81.5 \%$ of the total initial sample. This attrition rate compares very favorably to the attrition rates found in labor market surveys for developed countries (e.g., the attrition rate for the CPS is around 20\%). Among the 2,859 individuals initially randomly assigned, 2,359 or $82.2 \%$ of them are included in the follow-up survey. This low attrition rate is remarkable, especially considering that the data collection took place in a less developed country and for a subpopulation which is highly mobile. More importantly, attrition appears unrelated to random training offers. Results from a regression of an indicator of whether the person continues in the follow-up sample on an indicator of whether the person got a training offer show no relation between the random offer indicator and the probability of staying in the sample. ${ }^{15}$

\section{Data Description and Baseline Comparisons}

\subsection{Descriptive Statistics}

The baseline and follow-up surveys collected information for all individuals drawn both from the treatment and control populations and included three parts. The first part of the survey collected information on the demographic characteristics of all

\footnotetext{
${ }^{15}$ When the regression is run for the sample that includes the non-randomly assigned individuals, the coefficient on the selection dummy is 0.028 with an se of 0.015 for women and men together, 0.003 with an se of 0.02 for women and 0.054 with an se of 0.023 for men, so that if there is any selective attrition in this full sample it is driven by men.
} 
treatment and control individuals and those living in the same households. The second part included questions on education, training, health and general labor market information for all individuals older than 12 years of age living in the households of the treatment and control individuals. The third and most pertinent part of the survey included detailed questions to the treatment and control individuals on their labor market experience during the year prior to the survey. In addition, during the follow-up, questions were asked to those who participated in the program (treatment group) about their training experience.

Table 1 reports basic descriptive statistics on pre-treatment and post-treatment demographic characteristics and labor market outcomes of women and men in the treatment and control groups. The labor market variables include employment status, hours, days, earnings and the quality of jobs. We distinguish between employment and paid employment. We also distinguish between earnings from wage and salary employment and earnings from self-employment. As we discuss below, our earnings, tenure, days, and hours measures all include zeros for those not working. Two interesting outcomes that we consider in our analysis are whether the worker is employed in a formal sector job or not and whether she has a contract. These two measures are indicator variables which take the value of one if an individual is employed in the formal sector and has a written contract and zero if she is not working at all or works in the informal sector or without a written contract. This distinction between the formal and informal sector is important in developing countries where being in the formal sector implies access to pensions, health and other benefits as well as better working conditions. The Appendix includes a detailed description of how the various variables were constructed. 
The average age of women and men in the sample before training was around 21 years of age. About $54 \%$ of the sample is female. Close to a fifth of the individuals in the sample were married before the program started. Educational attainment among individuals in the sample is low. Average education was about 10 years of education before participation in the program and, thus, on average the individuals in the sample were high school dropouts. Employment during the year before training is low in terms of participation (i.e., the probabilities of employment and paid employment are close to 0.5 and 0.35), in terms of days worked per month (i.e., almost 12 days/month), and in terms of hours worked per week (i.e., about 25 hours/week). The probability of having had a formal sector job during the past year, which includes coverage for pensions, health insurance and/or injury compensation is only 0.08 . The probability of having had a job with a written contract is equally low. ${ }^{16}$ Moreover, wage and salary earnings and selfemployment earnings are also low. Monthly wage and salary earnings are 95,417 Colombian pesos or US $\$ 40.37 /$ month or US\$1.35/day. If these individual earnings were the only source of income in their households, then these individuals would be living in poverty or close to extreme poverty, as defined by the World Bank. Self-employment earnings are even lower.

\footnotetext{
${ }^{16}$ To get a sense of how our sample compares to the overall target population, we computed descriptive statistics from the 2005 National Household Surveys (NHS). In particular, we computed descriptive statistics for individuals between 18 and 25 years of age, living in the 7 cities where "Jóvenes en Acción" was implemented and who lived in households in the lowest two deciles of the income distribution in the 2005 NHS. Some of the statistics are remarkably close. For example, the mean age in this sample is 21 years and the share of women is 55.6. However, individuals in the NHS sample do better in some dimensions and worse in other dimensions compared to those in our Youth in Action sample. Those in the NHS sample have less education (9.2 years), are less likely to be employed (0.24), and are less likely to have a written contract $(0.26)$. On the other hand, those in the NHS sample are more likely to be employed in the formal sector (0.17) and to have longer tenure (5.3 months). These comparisons, thus, do not indicate whether our sample is unambiguously composed of better or worse individuals than the overall target population found in the NHS. Moreover, similar patterns hold for men and women, indicating that neither men nor women are unambiguously negatively or positively selected into the program.
} 


\subsection{Baseline Comparisons}

If the randomization was successful, the baseline characteristics of those not offered training (i.e., the control group) and those offered training (i.e., the treatment group) should not be significantly different at least within courses. They could, however, differ between training institutions and courses because these may differ in their quality and applicants may sort by training institution or courses on the basis of tastes, ability and other variables. Moreover, the probability of assignment to treatment differs by courses because in some cases there were not enough qualified applicants to assign $2 / 3$ to the treatment group and 1/3 to the control group as in the original design. For this reason, in addition to the simple comparison between treatment and control variable at baseline, we also make the same comparison allowing for course fixed effects.

Table 2 reports differences in demographic characteristics and labor market outcomes between the treatment and control groups at baseline. The first column reports simple comparisons for the baseline sample, while the second column reports baseline comparisons within courses. The first column shows that treatment and control group characteristics are, for the most part, very similar at baseline, i.e., before the program. The only exceptions are gender, tenure and education, which show significant but small differences between the two groups at the $5 \%$ and $1 \%$ levels, respectively. The treatment group has less than a third of a year more education and less than $5 \%$ more females. In addition, those in the treatment group appear to have one more month of tenure in their pre-treatment jobs. The second column controls for course fixed effects and, thus, relies on comparisons within types of courses. In this case, gender differences disappear, while tenure differences are now only marginally significant and differences in education 
remain significant but small, representing about $15 \%$ of a standard deviation for education.

\section{Estimating Program Effects}

Define by $Y_{1 i}$ and $Y_{0 i}$ the outcomes for individual $i$ in the training state and the non-training state. $\mathrm{D}_{\mathrm{i}}=\{0,1\}$ is an indicator of whether an individual chooses to participate in the program and is pre-selected by the training institution to which he applied. $\mathrm{R}_{\mathrm{i}}=\{0,1\}$ is an indicator of whether the individual was (randomly) offered a place in the program, following pre-selection by a training institution. Finally, $\mathrm{E}\{\bullet\}$ represents expectations.

Given the design of the program, we have that the average effect on the treated is equal to the average outcome for those randomly offered a place in a course C, i.e., $\mathrm{E}\left\{\mathrm{Y}_{1 \mathrm{i}} \mid \mathrm{D}_{\mathrm{i}}=1, \mathrm{C}\right\}=\mathrm{E}\left\{\mathrm{Y}_{\mathrm{i}} \mid \mathrm{D}_{\mathrm{i}}=1, \mathrm{C}, \mathrm{R}_{\mathrm{i}}=1\right\}$, where $\mathrm{Y}_{1 \mathrm{i}}$ represents the outcome in the treated state and $Y_{i}$ represents the observed outcome. Similarly, the counterfactual for this population may be estimated using the average outcome for those randomized out of a course, i.e., $E\left\{Y_{0 i} \mid D_{i}=1, C\right\}=E\left\{Y_{i} \mid D_{i}=1, C, R_{i}=0\right\}$, where $Y_{0 i}$ represents the outcome in the control state. The difference between these two expectations is the program effect in training course C,

$$
\delta_{\mathrm{T}}=\mathrm{E}\left\{\mathrm{Y}_{1 \mathrm{i}}-\mathrm{Y}_{0 \mathrm{i}} \mid \mathrm{D}_{\mathrm{i}}=1, \mathrm{C}\right\}=\mathrm{E}\left\{\mathrm{Y}_{\mathrm{i}} \mid \mathrm{D}_{\mathrm{i}}=1, \mathrm{C}, \mathrm{R}_{\mathrm{i}}=1\right\}-\mathrm{E}\left\{\mathrm{Y}_{\mathrm{i}} \mid \mathrm{D}_{\mathrm{i}}=1, \mathrm{C}, \mathrm{R}_{\mathrm{i}}=0\right\}
$$

Our estimator of the intention to treat is thus obtained as a weighted average of the within course effects, i.e.

$$
\hat{\delta}=\frac{\sum_{C} P_{C}\left(1-P_{C}\right)\left(\bar{Y}_{1 C}-\bar{Y}_{o C}\right)}{\sum_{C} P_{C}\left(1-P_{C}\right)}
$$


where $P_{C}$ is the probability of selection into the program among qualified applicants for a training course $\mathrm{C}, \bar{Y}_{1 c}$ is the average outcome (e.g., wages, employment) for those qualified applicants randomly offered training in course $\mathrm{C}$ and $\bar{Y}_{o c}$ is the average outcome for those qualified applicants randomly denied training in course C. The sum is taken over all training courses and the parameter is the weighted average of the program effects across training courses. ${ }^{17}$ This simple comparison of weighted means is an unbiased estimate of $\delta$, the intention-to-treat (ITT) effect. ${ }^{18}$

Recognizing that this is the standard within-groups estimator, it is straightforward to control for observable characteristics (see Arellano (2003)). Indeed, we control for age, education, a gender dummy, marital status, and city effects, all measured before training (pre-treatment) and henceforth denoted $\mathrm{X}_{\mathrm{i}}$. Including these pre-treatment characteristics increases the precision of the estimates and helps control for any remaining baseline imbalances, although these are insignificant for the most part and very small otherwise. In the tables below we report estimates that only control for course fixed effects and estimates that, in addition, control for pre-treatment characteristics.

If there was full compliance with random assignment, the ITT parameter just described would be the average effect of training on those who were deemed eligible and selected into the program. As shown in the next section, there was indeed close to fullcompliance with this program.

\footnotetext{
${ }^{17}$ Note that comparing within training courses would not be necessary if the probability of assignment of the treatment group did not vary by course type or if the effectiveness of training did not differ by type of course. As discussed above, the probability of treatment varies by training institution around a mean of 0.85 . Moreover, given the diversity of courses offered, the effectiveness of training is likely to vary across training institutions.

${ }^{18}$ This within estimator gives a bigger weight to observations in training institutions where individuals are equally likely to be assigned to the treatment and control groups. An alternative estimator would assign a bigger weight to observations in training institutions where the likelihood of being assigned to the treatment group is highest.
} 


\subsection{Effects of Random Offers on the Take-up of Training}

The description of the data above suggested that few individuals who were randomly offered training turned down training opportunities and few individuals not initially offered a spot in a training institution eventually got trained. To examine how close random training offers relate to actual training, we estimate a linear probability model of training on a random offer indicator, controlling for training course fixed effects and pre-treatment characteristics, as follows:

$$
T_{i j}=\alpha R_{i}+\rho X_{i}+\tau_{j}+v_{i j},
$$

where $T_{i j}$ is an indicator of whether person i obtained training in institution $j, X_{i}$ are pretreatment characteristics, $\tau_{\mathrm{j}}$ are training course fixed effects and $v_{\mathrm{ij}}$ is a random error term. Table 3 reports the results of this regression with and without pre-treatment controls. Random assignment to training increases the probability of being trained by 0.966 and 0.965 without and with pre-treatment characteristics, respectively. Thus, there is close to full compliance in the sense that most of those initially assigned to training get trained and most of those not initially assigned to the program remain untrained. This means that if we were to use the initial assignment as an instrumental variable for actual training the average effects on the treated would be between $3 \%$ and $4 \%$ higher than the intention-to-treat effects.

\subsection{Employment and Earnings Effects}

Panel A of Table 4 presents ITT effects which condition on training course fixed effects and city effects. These results show positive effects of being offered training on paid employment and on wage and salary earnings. On the other hand, tenure declines for those offered training. 
Panel B presents results which, in addition, control for all pre-training characteristics at once, including age, education, gender and marital status. The results conditioning on pre-treatment characteristics are somewhat smaller but remain large and significant. ${ }^{19}$ The results show that being offered training increases the probability of paid employment by 0.041 , as opposed to the 0.048 found without pre-treatment characteristics. The results for salaries also show smaller but still sizeable and significant effects of being offered training of about $12 \%$ compared to the control group.

At this point, it is useful to see how we can interpret the comparisons of earnings (including the zeros) between the treatment and control groups. The treatment effect we estimate is $E\left(S_{i} \mid R_{i}=1\right)-E\left(S_{i} \mid R_{i}=0\right)$, where $S_{i}$ stands for earnings (salary) and is set to zero if a person is out of work. Ignoring the pre-treatment characteristics for notational simplicity, this effect can be decomposed as

$$
\begin{gathered}
E\left(S_{i} \mid R_{i}=1\right)-E\left(S_{i} \mid R_{i}=0\right)=\left[E\left(S_{i} \mid L_{i}=1, R_{i}=1\right)-E\left(S_{i} \mid L_{i}=1, R_{i}=0\right)\right] \times \operatorname{Pr}\left(L_{i}=1 \mid R_{i}=0\right) \\
{\left[\operatorname{Pr}\left(L_{i}=1 \mid R_{i}=1\right)-\operatorname{Pr}\left(L_{i}=1 \mid R_{i}=0\right)\right] \times E\left(S_{i} \mid L_{i}=1, R_{i}=1\right)}
\end{gathered}
$$

where $\mathrm{L}_{\mathrm{i}}$ is an employment indicator. This expression shows that earnings increases will occur because of increased employment (the last term) and/or because of the increased earnings of those employed. Earnings of those employed could increase either because of increased productivity (due to improved skills provided by the program or due to improved matching as a result of the program) or due to access to better quality jobs. Finally, it is possible that the program changes the composition in terms of unobservables of those working, leading to a change in observed earnings. This kind of experiment

\footnotetext{
${ }^{19}$ When we control for one pre-training characteristic at a time, we find that the differences in results are driven by the inclusion of education.
} 
cannot distinguish the mechanism for increased earnings, even if employment did not change. Our results suggest that about a third of the increase in salaries can be accounted for by increases in paid employment and the rest is due to higher earnings among those employed who received the treatment relative to the controls. Although the positive effect does mean that the program caused average earnings to rise, the mechanism by which this happens is not revealed by this sort of approach because changes in employment composition cannot be controlled for. ${ }^{20}$

Returning to the results, the negative effects of being offered training on tenure are slightly larger and suggest a reduction in tenure of a little over one month, which is about a third of the time of the classroom training.

The picture is one of increased labor market activity with substantially higher wage and salary earnings and increased paid employment. ${ }^{21}$ On the basis of these results, this seems like a highly successful program for young individuals seeking training in the first $_{\text {place. }}{ }^{22}$

The only other similar intervention with a randomized trial in a developing country is the program in the Dominican Republic analyzed by Card et al. (2007), so it is

\footnotetext{
${ }^{20}$ For understanding more about whether the increase in earnings is due to increases in productivity or due to composition effects, an alternative would be to bound the impact on the quintiles of earnings for those in employment, using the approach developed by Manski (1994) and Blundell, Gosling, Ichimura and Meghir (2007). With this approach, means cannot be bounded without an assumption on the support of wages. This is, of course, a feature of any randomized experiment attempting to measure the effects on earnings, when the possibility of non-employment exists. However, given the large number of individuals without employment in our sample, the bounds are likely to be very wide so that this approach would not be very informative in our context. To get around the effects of censoring and to understand more about the mechanisms further assumptions and modeling would be required.

${ }^{21}$ While participation in the program may change the participants behavior and generate the so-called Hawthorn effects, the widespread positive impact of the program not only on earnings, but also on employment and the negative impact of the program on tenure suggest that the effects captured here are unlikely to simply reflect the participants reaction to being offered the subsidy for training.

${ }^{22}$ These results are consistent with the findings in Bettinger et al. (2007) showing that vouchers to attend vocational schools, which like the direct subsidy here reduce the costs of training, led to increased labor market participation and hours worked.
} 
of interest to provide a brief comparison of this program with "Jóvenes en Acción.” The programs are similar with the only difference that in Colombia the internship lasted 3 months instead of 2 months as in the Dominican Republic. Card et al. (2007) find no employment effect, but they do find an earnings effect of $10 \%$ to $17 \%$ (depending on the method used). However, the effect they find is not precisely estimated. There are some important differences in the design of the experiment and the data collection in our study and the Card et al. (2007) study. First, the Card et al. (2007) sample has 786 treatment and 563 controls as opposed to the 1,428 treatment and 1,431 control individuals in our sample. This can explain a reduction of standard errors by a factor of 1.42 in our study. Second, our results are based on the original random assignment to treatment, while the Card et al. (2007) study had to use data on the realized training outcome. Given that in the Dominican Republic there was substantial reassignment after the dropping out of the originally assigned trainees, this could introduce bias in their study. Nevertheless, the comparison between the two evaluations is valuable because of the similarity in program design and similarity in the magnitude of the results.

\subsection{Effects on Formal Sector Employment and Earnings}

In Latin America, like in other developing countries, there is a large share of workers employed in the shadow or informal economy, with no coverage of mandatory benefits. About $45 \%$ of all workers in Colombia are employed in jobs in the informal sector, in which they do not receive non-wage benefits such as health insurance, pensions, or injury compensation. ${ }^{23}$ Moreover, earnings are lower on average in the informal sector. While some of the earnings differences between the two sectors can be attributed to differences in skills and/or self-selection by ability of workers into the

\footnotetext{
${ }^{23}$ See, e.g., Kugler (1999, 2005).
} 
formal and informal sectors, wage differences remain between the two sectors even after controlling for observed and unobserved characteristics of workers and these are often attributed to the willingness of firms in the formal sector to pay above market-clearing wages. It is, thus, important to ask whether the intervention improved access to better paying jobs in the formal sector.

Table 5 shows intention-to-treat effects on the probability of formal employment, defined as employment covered by health, pension and injury compensation benefits, as well as on the probability of having a written contract. Not being employed in the formal sector includes the unemployed and those in the informal sector.

Panel A shows results controlling for course fixed effects and Panel B adds controls for pre-treatment characteristics. The results in the two panels show positive and significant effects on the probability of having a formal sector job and of having a written contract. Training offers increase the probability of having a formal sector job by 0.053 . The results also show that the offer of training increases the probability of having a written contract by 0.066 .

In addition to estimating the effect of the program on the probability of formal employment, we also try to get at whether the impact of training on wage and salary earnings that we documented earlier is due to higher earnings in these formal sector jobs. For this purpose, we estimate separate regressions of formal and informal wage and salary earnings, where formal earnings are assigned a zero when individuals are employed in the informal sector and where informal earnings are assigned a zero when individuals are employed in the formal sector. Training offers increase wage and salary earnings in the formal sector but not in the informal sector, indicating that the wage and 
salary earnings gains observed above are related to increased access to formal sector jobs.

As before, part of the higher formal salaries are due to increased formal sector employment, and the rest is due either to increased productivity or to differences in the composition of those in the formal sector. ${ }^{24}$ In addition, formal sector workers receive non-wage benefits which are paid through payroll taxes. This is an additional gain from training as long as non-wage benefits are not fully shifted to workers as lower wages. However, as noted in Kugler and Kugler (2009), only about 20\% of payroll taxes are passed on to workers as lower wages in the Colombian context, so that a large part of the non-wage benefits are accrued by the workers.

\subsection{Gender Differences}

Table 6 presents results of fully saturated models for women and men. Panel A presents results that control for course fixed effects, and Panel B presents results which also control for pre-treatment characteristics. The results for women in Columns (1) and (2) show positive effects on overall employment as well as on formal employment probabilities of 0.06 without controlling for pre-treatment characteristics and of 0.05 when controlling for these. Moreover, the results for women in Columns (3) and (4) show that the offer of training increases wage and salary earnings by $18 \%$ and formal earnings by $31 \%$. While the results in Columns (5)-(8) also show increased employment and earnings for men, the magnitudes are smaller and they are never significant.

Thus, the results above show larger and more widespread effects of training on women than on men. Women not only experience larger gains than men in terms of

\footnotetext{
${ }^{24}$ An alternative explanation for the higher formal sector earnings received by young treated workers is that these workers are simply earning temporarily higher earnings because they have steeper age-earnings profiles in the formal sector that eventually flatten. However, when we run a regression of earnings on age and age squared and the interaction of age and its quadratic term with a formal sector dummy, we find that the interaction terms are not individually or jointly significant.
} 
earnings following training, but they also experience gains in the quantity of employment in terms of participation not experienced by men. There are three possible reasons for the differential gains from training for women relative to men. First, the higher gains could result from the fact that women have lower levels of formal education to begin with. There are indeed small but significant differences in education between women and men before training, with women having on average 9.96 years of schooling and men having on average 10.2 years of schooling. However, interaction models which allow for a differential effect of training for those with different education levels show, if anything, bigger gains for those with higher formal educational attainment. Second, women with children received an additional stipend for child care, which may have freed up additional time for women to devote to training. However, the amount of training hours of women and men are not significantly different from each other. Third, qualitative interviews with the training institutions and trainees suggest that women were more motivated and were more responsible during the classroom and internship phases of the program. In fact, selfreported information on completion of the program show that $1.3 \%$ of men dropped out during the first three months of the program while only $1 \%$ of women did, though the difference is not statistically significant. However, only $0.4 \%$ of women were expelled from the classroom or internship phases, while $1.5 \%$ of men were expelled and this difference is significant at the $1 \%$ level. Although this differential expulsion may just reflect a different quality of original applicants to the program (in terms of unobservables) among women and men, it way also reflect the differences in effort put into training reported in the qualitative interviews by the program providers. 


\section{Cost-Benefit Analysis}

The simplest way of calculating a lower bound to the benefits of the program is to use the gains in wage and salary earnings. The results imply a gain of about 25,500 per month, so there are yearly gains of 306,000 Colombian pesos, which reflect employment and monthly earnings gains as well as salary earnings gains from moving to the formal sector. The results for women alone show even bigger gains of 30,000 per month or yearly gains of 360,000 Colombian pesos. The key question of course is whether these gains are permanent or not. We will consider two scenarios: one in which the gains are permanent but do not grow over time, and a second one in which we assume a $10 \%$ annual depreciation rate of these gains. We assume that the working life of these individuals is another 40 years, given that their average age is about 22 in the data. Discounting at $5 \%$ a year, and assuming the growth rate of earnings is not affected, we obtain a gain of US\$2,344 for men and women and of US\$2,749.96 for women alone under the first scenario in which the gains are permanent. Under the more conservative scenario in which we allow the gains to depreciate at a rate of $10 \%$ annually, the gains are of $\$ 906.25$ for both men and women and of US $\$ 1,066.18$ for women alone.

The direct cost of operation of the training program was US\$750 per person. Under the first scenario of permanent gains, the net gains are of $\$ 1,594.9$ for men and women together and of $\$ 1999.96$ for women. Under the more conservative scenario which allows for depreciation of these gains, there is a net benefit of $\$ 156.25$ for men and women and of \$ 316.18 for women alone. Thus, net benefits from the program are positive and large when the gains are assumed to persist over time. Moreover, even when we allow for workers to loose some of the skills learned during training, the program is 
still cost-effective though the gains are not as large. On the other hand, this is clearly a conservative estimate given that we have not considered the non-wage benefits received due to the increased employment in the formal sector for both women and men.

Another way of calculating the effectiveness of the program is to calculate the internal rate of return. The internal rate of return is the rate of return that equates the costs with the gains. Under the first scenario the internal rate of return is $17.5 \%$ for both men and women and $20.5 \%$ for women, while under the more pessimistic scenario, which allows for depreciation, the rate of return is $8 \%$ for men and women and $12 \%$ for women. These high rates of return suggest that the training program was a great success, given that real interest rates at the time in Colombia were between $6 \%$ and $7 \%$.

While it is possible that the program encouraged the creation of new jobs by increasing the supply of qualified workers and by improving intermediation in the labor market, some of the gains for program participants could have come at the expense of displacing some non-participants. We can re-estimate our net gains making assumptions about the extent of displacement. ${ }^{25}$ If we assume half of the gains of the program came at the expense of displacing previously employed individuals, then the gains are $\$ 1,172.45$ for both men and women and $\$ 1,374.98$ for women under the no depreciation scenario. Thus, under no depreciation, the program yields positive net gains of $\$ 422.45$ fort both men and women and $\$ 624.98$ for women even if assuming that half of the program participants' gains come at the expense of displacing other youth in the labor market. If we allow for depreciation and displacement, the net gains would still be positive for women if only a fourth of the participants displaced non-participants.

\footnotetext{
${ }^{25}$ An alternative way to get at the importance of displacement is to randomize both between and within regions as in Blundell et al. (2004). However, this cannot be done in the Colombian context, since randomization was only conducted within regions.
} 
Finally, it should be noted that in a large scale implementation of a program like Youth in Action, general equilibrium effects may become a very important consideration. These would need to be taken into account when implementing such a program. The final impact will depend on the degree to which various labor inputs are substitutable for each other, with high levels of substitution implying smaller general equilibrium effects.

The high returns to training, at least for women, beg the question as to why more people are not getting trained on their own. In the case of “Jóvenes en Acción”, there was a shortage of volunteers for some courses once the program was announced, which suggests that lack of information may be preventing people from obtaining training. In addition, a credible hypothesis is that they cannot finance it. Indeed, it would take about 22 months of pay to cover the entire cost, based on the average pay at the time the program was initiated. Moreover, the costs would be even higher for women with children who would need to cover for childcare costs during their participation in the program. It is unlikely that anyone would be able to borrow such an amount without collateral at a reasonable interest rate.

\section{Conclusion}

The program “Jóvenes en Acción” introduced in Colombia in 2005 offers a unique opportunity to evaluate the causal effect of training on young people with little education in the context of a less-developed country. The program offered vocational training for a total period of 6 months (3 months in classroom and 3 months on-the-job) to young unemployed men and women, who belonged to the lowest two strata in the population and who were for the most part high-school dropouts. Most importantly for 
the purpose of this evaluation, the program randomly offered training to these young men and women. The results show that the program had substantial effects. In particular, training increased wage and salaried earnings and the probability of a having paid employment. In particular, salaried earnings increased by $12 \%$ for all individuals and by $18 \%$ for women alone. As is standard in these interventions, there is some loss in work experience due to the time in the classroom, which is reflected in loss of tenure for the treatment group. In particular, we find a decrease in tenure of a little over one month. The results are robust to controlling for course fixed effects and pre-treatment characteristics. This is reassuring, but not surprising, given the randomized design of the evaluation and the fact that treatment and control samples are reasonably balanced at baseline.

Our results show that training offers increase earnings both due to increased employment and due to increases in productivity and access to better jobs. We find an increase in the probabilities of having a formal sector job and a written contract of 0.053 and 0.066, respectively, suggesting that part of the increased earnings for those trained is likely due to access to better jobs.

These results constitute the basis for a cost-benefit analysis. Even the most conservative of the cost-benefit calculations, which ignore the benefits associated to the higher probability of being employed in the formal sector and which allow the benefits to depreciate over time, suggest that the net benefits of the program more than justify its existence and possibly its expansion. Under this pessimistic scenario, the internal rate of return is of $8 \%$ for both men and women and $12 \%$ for women only, while under the more optimistic scenario which does not allow for depreciation the internal rate of return is of $17.5 \%$ for both men and women and $20.5 \%$ for women alone. Moreover, even allowing 
for half of the gains of the participants to come at the expense of displacing nonparticipants, the net gains are still positive. Given the high returns to training, the question remains as to why similar type of programs are not more widespread and why people do not take advantage of existing training opportunities. Lack of information and credit constrains are two likely causes, but this remains an open question.

By most standards, including cost-benefit criteria, Youth in Action is a success, especially for women. This contrasts with results obtained in industrialized countries, such as the US, the UK and others, as discussed earlier. A priori, there is little reason to expect that in such different contexts the results should be similar. However, it is still useful to highlight, what aspects of this program may have contributed to making it successful.

First, the program provided six months of specific skills in certain sectors or occupations in the classroom and on-the-job suggesting an important specific human capital component to the training. Second, private sector institutions - some for-profit and some non-profit, offered the classroom training and chose, designed and marketed the courses to the firms providing the internships. Training institutions, thus, had to offer courses which provided skills for which there was demand in the labor market. There is already some evidence that both these aspects are important for the success of training programs. ${ }^{26}$ Third, the internships allowed both firms and workers to obtain information on the other side of the market. From the employers' side, the internships allow firms to acquire information on the quality of workers without having to commit with a written contract subject to the high dismissal costs in Colombia. From the workers' side, the

\footnotetext{
${ }^{26}$ Sianesi (2003) for example shows that among the Swedish programs the ones relating to wage subsidies and internships are the most successful. Blundell, Dearden and Meghir (1996) show that private employerprovided training is the one with positive returns.
} 
internships provide information on jobs just becoming available that are not announced through formal channels as well as information on what sort of skills are required for a job.

Our results are consistent with the reasoning underlying the recent recommendation by the Economic Commission for Latin America and the Caribbean (ECLAC) "[to establish] a national training and skills development system which provides internships in business and links to employers" as a solution to the youth unemployment problem in the region (Hopenhayn (2002)). Given these perceptions, it would be worthwhile to further explore the causal impact of on-the-job versus classroom training on youth labor market success as well as the differential impact of training versus job search assistance which is directly designed to improve matches. 


\section{References}

Ado, Christian and Sergio Nuñez. 2004. "The Impact of Training Policies in Latin America and the Caribbean: The Case of Program Jove.” IDB Working Paper No. R-483.

Angrist, Joshua, Eric Bettinger, Eric Bloom, Elizabeth King, and Michael Kremer. 2002. "Vouchers for Private Schooling in Colombia: Evidence from a Randomized Natural Experiment.” American Economic Review, 92(5): 1535-59.

Angrist, Joshua, Eric Bettinger and Michael Kremer. 2006. “Long-term Educational Consequences of Secondary School Vouchers: Evidence from Administrative Records in Colombia.” American Economic Review, 96(3): 847-862.

Arellano Manuel. 2003. Panel Data Econometrics. Oxford: Oxford University Press.

Ashenfelter, Orley. 1978. "Estimating the Effects of Training Programs on Earnings." Review of Economics and Statistics, 60(1): 648-660.

Attanasio, Orazio, Emla Fitzsimons, Alice Mesnard and Marcos Vera-Hernandez. 2005. "How Effective are Conditional Cash Transfers? Evidence from Colombia." IFS Working Paper No. 54.

Banerjee, Abhijit, Shawn Cole, Esther Duflo, and Leigh Linden. 2007. "Remedying Education: Evidence from Two Randomized Experiments in India.” Quarterly Journal of Economics, 122(3): 1235-1264.

Barrera-Ozorio, Felipe, Marianne Bertrand, Leigh Linden and Francisco Peres-Calle. 2008. "Conditional Cash Transfers in Education: Design Features, Peer and Sibling Effects. Evidence from a Randomized Experiment in Colombia.” NBER Working Paper No. 13890.

Behrman, Jere, Pilali Sengupta and Petra Todd. 2005. "Progressing Through PROGRESA: An Impact Assessment of a School Subsidy Experiment in Mexico.” Economic Development and Cultural Change, 54(1): 237-275.

Betcherman, Gordon, Karina Olivas and Amit Dar. 2004. "Impacts of Active Labor Market Programs: New Evidence from Evaluations with Particular Attention to Developing and Transition Countries.” World Bank Social Protection Discussion Paper Series No.0402.

Bettinger, Eric, Michael Kremer, and Juan Saavedra. 2008. “Are Educational Vouchers Only Redistributive?" http://www.povertyactionlab.org/papers/Are\%20educational\%20vouchers\%20only\%20di stributive\%20Colombia.pdf. 
Blundell, Richard, Lorraine Dearden and Costas Meghir. 1996. The Determinants and Effects of Work Related Training in Britain. Oxon: PsychoBabel Books.

Blundell, Richard, Monica Costa Dias, Costas Meghir and John Van Reenen. 2004. "Evaluating the Employment Impact of a Mandatory Job Search Assistance Program." Journal of the European Economic Association, 2(4): 569-606.

Blundell, Richard, Amanda Gosling, Hidechiko Ichimura and Costas Meghir. 2007. "Changes in the Distribution of Male and Female Wages Accounting for Employment Composition Using Bounds.” Econometrica, 75(2): 323-363.

Burghardt, John and Peter Schochet. 2001. National Job Corps Study: Impact by Center Characteristics. Princeton: Mathematica Policy Research.

Card, David, Pablo Ibarrarán, Ferdinando Regalia, David Rosas, and Yuri Soares. 2007. "The Labor Market Impact of Youth Training in the Dominican Republic: Evidence from a Randomized Evaluation.” NBER Working Paper No. 12883.

Card, David and Daniel Sullivan. 1988. "Measuring the Effect of Subsidized Training Programs on Movements In and Out of Employment.” Econometrica, 56(3): 497-530.

Carneiro, Pedro and James Heckman. 2003. "Human Capital Policy,” In Inequality in America: What Role for Human Capital Policies?, eds., James Heckman and Alan Krueger, 77-240. Cambridge, MA: MIT Press.

Calderon-Madrid, Angel. 2006. "Revisiting the Employability Effects of Training Programs for the Unemployed in Developing Countries.” IDB Working Paper No. R-522.

Chong, Alberto and José Galdo. 2006. "Does the Quality of Training Programs Matter? Evidence from Bidding Processes Data.” IZA Working Paper No. 2202.

Duflo, Esther. 2001. "Schooling and Labor Market Consequences of School Construction in Indonesia: Evidence from an Unusual Policy Experiment.” American Economic Review, 91(4): 795-813.

Elias, Victor, Fernando Ruiz, Ricardo Cossa, and David Bravo. 2004. “An Econometric Cost-Benefit Analysis of Argentina's Youth Training Program.” IDB Working Paper No. R-482.

Gill, Indermit, Claudio Montenegro and Dörte Dömeland. 2002. Crafting Labor Policy: Techniques and Lessons from Latin America. Washington, D.C.: The World Bank.

Glewwe, Paul and Pedro Olinto. 2004. "Evaluating the Impact of Conditional Cash Transfers on Schooling: An Experimental Analysis of Honduras PRAF Program.” Report for IFPRI. 
Heckman, James, and Alan Krueger. 2003. Inequality in America: What Role for Human Capital Policies? Cambridge, MA: MIT Press.

Heckman, James, Robert LaLonde and Jeffrey Smith. 1999. "The Economics and Econometrics of Active Labor Market Programs.” In Handbook of Labor Economics, Vol. 3A, eds., Orley Ashenfelter and David Card, pp. 1865-2097. Amsterdam: North Holland.

Heckman, James, Hidehiko Ichimura, Jeffrey Smith, Petra Todd. 1998. "Characterizing Selection Bias Using Experimental Data.” Econometrica, 66(5): 1017-1098.

Hjort, Jonas, Michael Kremer, Isaac Mbiti and Edward Miguel. "Vocational Education Vouchers and Labor Market Returns: A Randomized Evaluation Among Kenyan Youth.” Unpublished manuscript, UC. Berkeley, Harvard and Southern Methodist University.

Holzer, Harry. 2007. "What Might Improve the Employment and Advancement Prospects for the Poor?" Paper presented at the Federal Reserve Bank of Chicago Conference on Strategies for Improving Economic Mobility of Workers, Chicago, IL.

Hopenhayn, Martin. 2002. "Youth and Employment in Latin America and the Caribbean: Problems, Prospects and Options.” ECLAC Working Paper.

Ibarrarán, Pablo and David Rosas. 2007. "Impact Evaluation of a Labor Training Program in Panama.” Unpublished manuscript, IDB.

Kremer, Michael and Christel Vermeersh. 2005. "School Meals, Educational Achievement, and School Competition: Evidence from a Randomized Evaluation," World Bank Working Paper No. 3523.

Kugler, Adriana and Maurice Kugler. 2009. "The Labor Market Effects of Payroll Taxes in Developing Countries: Evidence from Colombia." Economic Development and Cultural Change, 57(2): 335-358.

Kugler, Adriana. 2005. "Wage-Shifting Effects of Severance Payments Savings Accounts in Colombia." Journal of Public Economics, 89(2-3): 487-500.

Kugler, Adriana. 1999. "The Impact of Firing Costs on Turnover and Unemployment: Evidence from the Colombian Labor Market Reform." International Tax and Public Finance Journal, 6(3): 389-410.

LaLonde, Robert. 1995. "The Promise of Public Sector Sponsored Training Programs.” Journal of Economic Perspectives, 9(2): 149-168.

LaLonde, Robert. 1986. "Evaluating the Econometric Evaluations of Training Programs with Experimental Data.” American Economic Review, 76(4): 604-620. 
Malamud, Ofer and Cristian Pop-Eleches. Forthcoming. "General Education versus Vocational Training: Evidence from an Economy in Transition.” Review of Economics and Statistics.

Manski, Charles. 1994. “The Selection Problem.” In Christopher Sims, ed., Advances in Econometrics, ed., Christopher Sims, 143-170. Cambridge, U.K.: Cambridge University Press.

Muralidharan, Kartik and Venkatesh Sundararaman. 2006. "Teacher Incentives in Developing Countries: Experimental Evidence from India.” http://www.povertyactionlab.org/papers/Are\%20educational\%20vouchers\%20only\%20di stributive\%20Colombia.pdf.

Orr, Larry, Howard Bloom, Stephen Bell, Winston Lin, George Cave and Fred Doolittle. 1994. The National JTPA Study: Impacts, Benefits, and Costs of Title II-A. Bethesda, MD: Abt Associates.

Smith, Jeffrey and Petra Todd. 2001. "Reconciling Conflicting Evidence on the Performance of Propensity Score Matching Methods.” American Economic Review, 91(2): 112-118.

Sianesi, Barbara. 2003. "Swedish Active Labour Market Programmes in the 1990s: Overall Effectiveness and Differential Performance.” Swedish Economic Policy Review, 8(2): 133-169.

World Bank. 2007. World Development Report. Washington D.C.: The World Bank. 


\section{Data Appendix}

All information used in this analysis was originally collected for the purpose of evaluating the program "Jóvenes en Acción.” The data was collected by enumerators who visited the households of individuals in the treatment and control groups on average 3 times. The survey consisted of three parts. The first part collected information on the characteristics of the household, including demographic characteristics of all members of the household as well as household expenditures. The second part of the survey collected information on education, general labor market experience and health outcomes of all household members over the age of 12. Finally, the last part of the survey collected detailed labor market information exclusively on young individuals assigned either to the treatment or control groups. The information in the filled surveys was scanned; read by computers, and subsequently checked for reading errors.

Employment and Paid Employment: the employment variable is an indicator variable which takes the value of 1 if the person reports to have had a job during the year after finishing training or 0 if the person reports being unemployed or out of the labor force. Paid employment is slightly different as it also assigns a value of zero to those who report being employed but who report having zero earnings. There are 176 women and 179 men who report having being employed but having earnings of zero.

Weeks and Hours Worked: the survey asks the weeks worked per month and the hours worked per week on the main job held during the year after finishing training. We impute zero weeks and hours worked for all of those who reported being either unemployed or out of the labor force during the year following the completion of the training program.

Formal Employment: formal employment is an indicator variable which takes the value of 1 if the worker was covered by health insurance, injury compensation, pensions or family subsidies, and zero if the worker did not receive any of these benefits in the main job held during the year after having finished training. We impute zeros for all individuals who report being either unemployed or out of the labor force during the entire year after the completion of the program.

Written Contract: written contract is an indicator variable which takes the value of 1 if the person reports having signed a written contract in the most important job during the year following the completion of the program and zero if the person did not sign a contract in the most important job or was unemployed or out of the labor force during the year following the completion of the program. Note that this is different from having a permanent or a temporary contract, but rather refers to having any type of written contract whatsoever.

Tenure: the tenure on the most important job during the year following the completion of the program is constructed by using the exact dates (month and year) when the person reported ending and starting the most important job held during the year after the completion of the program. For those who reported to still be in the same jobs, the end date used was the month and year of the interview so that tenure spells were incomplete. 
We also imputed zero tenure spells for all individuals who reported being unemployed or out of the labor force during the year following the completion of the training program.

Wage and Salary Earnings and Self-Employment Earnings: wage and salary earnings are the monthly salaries and wages earned in the main job held during the year after having finished training for salaried workers. Self-employment earnings are the monthly earnings net of costs for the self-employed. We impute zero earnings for all of those who reported being either unemployed or out of the labor force. Earnings are deflated by a city-specific CPI, which comes from the National Department of Statistics (DANE).

Formal and Informal Wage and Salary Earnings: formal wage and salary earnings are the monthly salaries and wages earned in the main formal job held during the year after having finished training for salaried workers. Similarly, informal wage and salary earnings are the monthly salaries and wages earned in the main informal job held during the year after having finished training for salaried workers. We impute zero earnings for those who reported being either unemployed or out of the labor force. For formal earnings, we impute zero earnings for all of those who were identified as employed in the informal sector. By contrast, for informal earnings, we impute zero earnings for all of those who were identified as employed in the formal sector. As before, earnings are deflated by a city-specific CPI. 
Table 1: Basic Descriptive Statistics of Pre- and Post-Treatment Variables

\begin{tabular}{|c|c|c|}
\hline & Pre-Treatment 2004 & Post-Treatment 2006 \\
\hline Employment & $\begin{array}{c}0.496 \\
(0.500)\end{array}$ & $\begin{array}{c}0.736 \\
(0.441)\end{array}$ \\
\hline Paid Employment & $\begin{array}{c}0.352 \\
(0.478)\end{array}$ & $\begin{array}{c}0.631 \\
(0.483)\end{array}$ \\
\hline $\begin{array}{l}\text { Contract (zero if out of } \\
\text { work) }\end{array}$ & $\begin{array}{c}0.073 \\
(0.260)\end{array}$ & $\begin{array}{c}0.252 \\
(0.435)\end{array}$ \\
\hline $\begin{array}{l}\text { Formal (zero if out of } \\
\text { work) }\end{array}$ & $\begin{array}{c}0.080 \\
(0.271)\end{array}$ & $\begin{array}{c}0.272 \\
(0.445)\end{array}$ \\
\hline Wage and Salary & 95,417 & 227,056 \\
\hline $\begin{array}{l}\text { Earnings (zero if out of } \\
\text { work) }\end{array}$ & $(150,513)$ & $(209,526)$ \\
\hline Self-employment & 22,019 & 21,374 \\
\hline $\begin{array}{l}\text { Earnings (zero if } \\
\text { missing) }\end{array}$ & $(78,338)$ & $(82,862)$ \\
\hline $\begin{array}{l}\text { Tenure (zero if out of } \\
\text { work) }\end{array}$ & $\begin{array}{c}3.354 \\
(8.164)\end{array}$ & $\begin{array}{c}7.728 \\
(13.741)\end{array}$ \\
\hline $\begin{array}{l}\text { Days Worked per Month } \\
\text { (zero if out of work) }\end{array}$ & $\begin{array}{c}11.919 \\
(12.711)\end{array}$ & $\begin{array}{c}17.382 \\
(11.771)\end{array}$ \\
\hline $\begin{array}{l}\text { Hours Worked per Week } \\
\text { (zero if out of work) }\end{array}$ & $\begin{array}{c}24.957 \\
(28.693)\end{array}$ & $\begin{array}{l}38.078 \\
(27.651)\end{array}$ \\
\hline Education & $\begin{array}{l}10.076 \\
(1.806)\end{array}$ & $\begin{array}{l}10.297 \\
(1.660)\end{array}$ \\
\hline Age & $\begin{array}{l}21.188 \\
(2.048)\end{array}$ & $\begin{array}{l}22.764 \\
(2.110)\end{array}$ \\
\hline Married & $\begin{array}{c}0.193 \\
(0.395)\end{array}$ & $\begin{array}{c}0.265 \\
(0.442)\end{array}$ \\
\hline Max N & 2,859 & 2,349 \\
\hline
\end{tabular}

Notes: The table reports means and standard deviations of the labor market outcomes and demographic characteristics for the pre-training period and the post-training period, combining treatment and control groups. 
Table 2: Baseline Differences between Treatment and Control Groups

\begin{tabular}{|c|c|c|}
\hline & $\begin{array}{c}\text { Pre-Training } 2004 \\
\text { No Course Fixed } \\
\text { Effects }\end{array}$ & $\begin{array}{c}\text { Pre-Training } 2004 \\
\text { Course Fixed } \\
\text { Effects }\end{array}$ \\
\hline Employment & $\begin{array}{c}0.001 \\
(0.021)\end{array}$ & $\begin{array}{l}-0.010 \\
(0.021)\end{array}$ \\
\hline Paid Employment & $\begin{array}{c}0.024 \\
(0.020)\end{array}$ & $\begin{array}{c}0.018 \\
(0.020)\end{array}$ \\
\hline Contract (0 if no work) & $\begin{array}{l}-0.000 \\
(0.011)\end{array}$ & $\begin{array}{c}0.001 \\
(0.011)\end{array}$ \\
\hline Formal (0 if no work) & $\begin{array}{c}0.005 \\
(0.011)\end{array}$ & $\begin{array}{c}0.006 \\
(0.011)\end{array}$ \\
\hline Wage and Salary & 850 & $-6,806$ \\
\hline Earnings (0 if no work) & $(5,922)$ & $(6,000)$ \\
\hline Self-employment & $-3,414$ & $-3,002$ \\
\hline Earnings (0 if missing) & $(3,394)$ & $(5,460)$ \\
\hline Tenure (0 if no work) & $\begin{array}{c}0.942 * * \\
(0.410)\end{array}$ & $\begin{array}{c}0.768 * \\
(0.440)\end{array}$ \\
\hline $\begin{array}{l}\text { Days Worked per Month } \\
\text { (0 if no work) }\end{array}$ & $\begin{array}{c}0.188 \\
(0.531)\end{array}$ & $\begin{array}{l}-0.312 \\
(0.535)\end{array}$ \\
\hline $\begin{array}{l}\text { Hours Worked per Week } \\
\text { (0 if no work) }\end{array}$ & $\begin{array}{l}-0.074 \\
(1.185)\end{array}$ & $\begin{array}{l}-1.436 \\
(1.190)\end{array}$ \\
\hline Women & $\begin{array}{l}0.046^{* *} \\
(0.018)\end{array}$ & $\begin{array}{c}0.262 \\
(0.174)\end{array}$ \\
\hline Education & $\begin{array}{c}0.257 * * * \\
(0.083)\end{array}$ & $\begin{array}{c}0.280 * * * \\
(0.072)\end{array}$ \\
\hline Age & $\begin{array}{l}-0.113 \\
(0.081)\end{array}$ & $\begin{array}{l}-0.090 \\
(0.085)\end{array}$ \\
\hline Married & $\begin{array}{l}-0.009 \\
(0.019)\end{array}$ & $\begin{array}{l}-0.015 \\
(0.020)\end{array}$ \\
\hline $\operatorname{Max} N$ & 2,858 & 2,269 \\
\hline
\end{tabular}

Notes: The table reports differences in mean baseline characteristics between the treatment and control groups with and without course fixed effects. * indicates significance at the $10 \%$ level, ** indicates significance at the $5 \%$ level, and *** indicates significance at the $1 \%$ level. 
Table 3: Effect of Training Offer on Probability of Being Trained

\begin{tabular}{lcc}
\hline \hline & $(1)$ & $(2)$ \\
\hline Training Offer & $0.966^{* * *}$ & $0.965^{* * *}$ \\
$\mathrm{~N}$ & $(0.005)$ & $(0.005)$ \\
& 2,857 & 2,850 \\
$\begin{array}{l}\text { City Effects } \\
\text { Pre-treatment } \\
\text { Characteristics }\end{array}$ & Yes & Yes \\
Course Fixed Effects & No & Yes \\
\hline \hline
\end{tabular}

Notes: The table reports the effect of being randomly offered training on the probability of having being trained. Robust standard errors are in parenthesis. $* * *$ indicates significance at the $1 \%$ level. 
Table 4: Intention-to-Treat Estimates of Effects of Training

on Employment and Earnings

Labor Supply Earnings

$\underline{\text { Employment }} \quad \underline{\text { Paid }} \quad \underline{\text { Dmployment }} \quad \underline{\text { Days/Month }} \quad \underline{\text { Hours/Week }} \quad \underline{\text { Tenure }} \quad \underline{\text { Wage \& Salary Self-employment }}$

$\begin{array}{llllllll}\text { Control } & 0.723 & 0.603 & 16.903 & 37.472 & 8.781 & 209,017 & 23,260\end{array}$

A. Course Fixed Effects

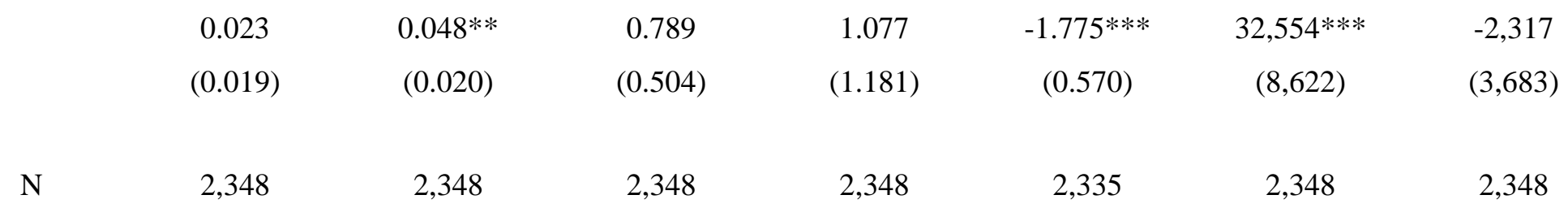

B. Course Fixed Effects and Pre-treatment Characteristics

\begin{tabular}{cccccccc} 
& 0.018 & $0.041^{* *}$ & 0.609 & 0.738 & $-1.211^{* * *}$ & $25,475^{* * *}$ & $-2,283$ \\
& $(0.018)$ & $(0.020)$ & $(0.49882)$ & $(1.170)$ & $(0.462)$ & $(8,555)$ & $(3,660)$ \\
& & & & & & \\
& & & & & & & \\
& 2,342 & 2,342 & 2,342 & 2,161 & 2,432 & \\
\hline
\end{tabular}

Notes: The table reports the coefficient of the training offer dummy for separate regressions of labor market outcomes. Robust standard errors are reported in parenthesis. All regressions control for course fixed effects. The regressions in Panel B control for pre-training age, education, a gender dummy, a marital status dummy, and city effects. * indicates significance at the $10 \%$ level, ** indicates significance at the $5 \%$ level, and *** indicates significance at the $1 \%$ level. 
Table 5: Intention-to-Treat Estimates of Effects of Training on Formal Employment and Earnings

\begin{tabular}{|c|c|c|c|c|}
\hline \multirow[b]{2}{*}{$\begin{array}{l}\text { Control } \\
\text { Means }\end{array}$} & $\underline{\text { Contract }}$ & $\begin{array}{c}\text { Formal } \\
\text { Employment }\end{array}$ & $\begin{array}{l}\text { Formal } \\
\underline{\text { Salary }}\end{array}$ & $\underline{\text { Informal }}$ \\
\hline & 0.205 & 0.235 & 98381 & 110636 \\
\hline \multicolumn{5}{|c|}{ A. Course Fixed Effects } \\
\hline \multirow{4}{*}{$\mathrm{N}$} & $\begin{array}{c}0.078^{* * *} \\
(0.019)\end{array}$ & $\begin{array}{c}0.063 * * * \\
(0.019)\end{array}$ & $\begin{array}{c}29,553 * * * \\
(8,469)\end{array}$ & $\begin{array}{l}59.607 \\
(7,565)\end{array}$ \\
\hline & 2,348 & 2,348 & 2,348 & 2,348 \\
\hline & \multicolumn{4}{|c|}{ B. Course Fixed Effects and Pre-training Characteristics } \\
\hline & $\begin{array}{c}0.066^{* * *} \\
(0.018)\end{array}$ & $\begin{array}{c}0.053 * * * \\
(0.019)\end{array}$ & $\begin{array}{c}24,872 * * * \\
(8,390)\end{array}$ & $\begin{array}{c}603 \\
(7,584)\end{array}$ \\
\hline $\mathrm{N}$ & 2,342 & 2,342 & 2,342 & 2,342 \\
\hline
\end{tabular}

Notes: The table reports the coefficient of the training offer dummy for separate regressions of labor market outcomes. Robust standard errors are reported in parenthesis. All regressions control for course fixed effects. The regressions in Panel B control for pre-training age, education, a gender dummy, a marital status dummy, and city effects. * indicates significance at the $10 \%$ level, ** indicates significance at the $5 \%$ level, and $* * *$ indicates significance at the $1 \%$ level. 
Table 6: Intention-to-Treat Estimates of Effects of Training on Formal Employment and Earnings of Women and Men Separately

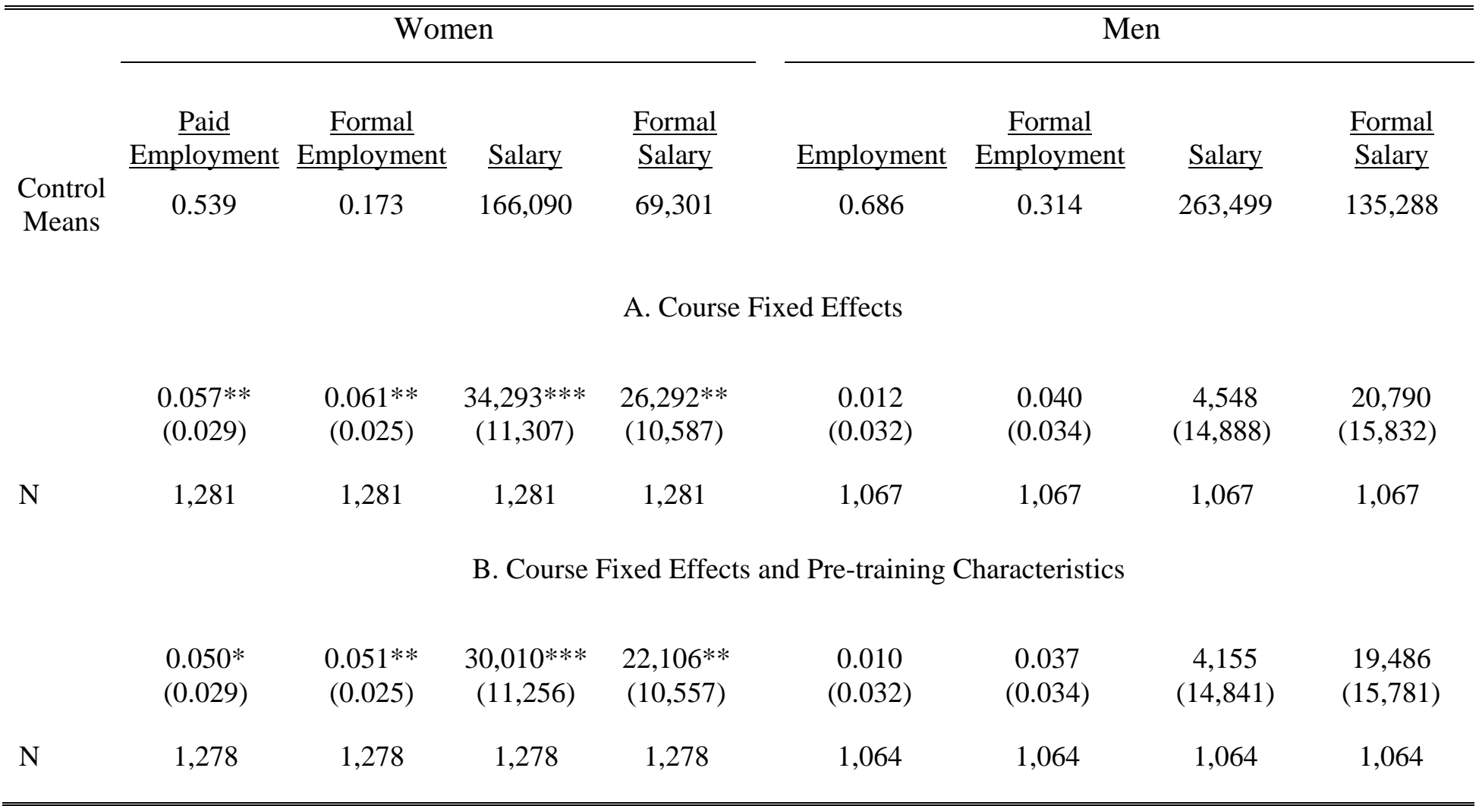

Notes: The table reports the coefficient of the training offer dummy for separate regressions of labor market outcomes for women and men separately. Robust standard errors are reported in parenthesis. All regressions control for course fixed effects. The regressions in Panel B control for pre-training age, education, a marital status dummy, and city effects. * indicates significance at the $10 \%$ level, ${ }^{* *}$ indicates significance at the $5 \%$ level, and $* * *$ indicates significance at the $1 \%$ level. 